\title{
Variation in the branching pattern of celiac trunk: a case report
}

\author{
NAYAK, S. B., AITHAL, A. P. *, SHETTY, S. D., KUMAR, N., RAVINDRA, \\ S. S. and RAO, S. S.
}

Department of Anatomy, Melaka Manipal Medical College, Manipal University, Manipal Campus, 576104, Manipal, Karnataka, India

*E-mail: ashwini.anat@gmail.com

\begin{abstract}
Arterial supply for the derivatives of foregut in the abdomen is provided by the branches of the celiac trunk. Celiac trunk is the first ventral branch of abdominal aorta and usually branches into splenic, common hepatic and left gastric arteries. Variations in the branching pattern of celiac trunk are common but in most of the people, they remain asymptomatic and go unnoticed. A good knowledge of these anatomical variations is important for surgeons undertaking various surgeries in the abdominal region and will help to minimise the complications related to abdominal surgery. Clinicians and radiologists should also be aware of any variations in the vascular pattern of the celiac trunk before performing angiographic examinations. In the current case, the celiac trunk divided into two branches; left gastric artery and hepato-splenic trunk. The hepato-splenic trunk further divided into splenic and common hepatic arteries. The common hepatic artery trifurcated into proper hepatic, gastroduodenal and accessory hepatic arteries. Hepatic artery proper divided into right and left hepatic arteries. The accessory hepatic artery was tortuous and was as large as the left hepatic artery. It gave origin to the right gastric artery and entered the liver through left end of porta hepatis.
\end{abstract}

Keywords: celiac trunk, common hepatic artery, splenic artery, accessory hepatic artery, right gastric artery.

\section{Introduction}

The celiac trunk is the first ventral branch of the abdominal aorta and it arises just below the aortic hiatus, at the level of the T12-Ll vertebra. It is 1.5 to $2 \mathrm{~cm}$ long and it passes almost horizontally forwards and divides into the left gastric, the common hepatic and the splenic arteries. The hepatic artery is further subdivided into a common hepatic part, which extends from the coeliac trunk to the origin of the gastroduodenal artery and the hepatic artery proper, which extends from that point to its bifurcation (STANDRING, 2008). The branches of celiac trunk namely left gastric, common hepatic and splenic arteries supply mainly the stomach, pancreas, spleen and liver. This trifurcation was first described by Haller in 1756 . This "Tripus Halleri" was and is still being considered to be the normal appearance of the coeliac trunk (HEMANTH, GARG, YADAV et al., 2011). Anomalous branching pattern of celiac trunk have been reported in the past by many researchers. The normal pattern of trifurcation of celiac trunk was observed in $87.6 \%$, bifurcation and incomplete division in $12.2 \%$ and very rarely absence of it in $0.2 \%$ of cases (UCERLER and IKIZ, 2006; BERGMAN, AFIFI and MIYAUCHI, 2011).

Variations in the branching pattern of celiac trunk may lead to iatrogenic injury during various abdominal surgeries such as total pancreatomy (GIELECKI, ZURADA, SONPAL et al., 2005) resection of tumors of head of pancreas (LIN, 2005) or any other surgical procedures of upper abdomen.

Also, knowledge of such variations may be useful in planning and executing radiological interventions such as celiacography (GLUCK, GERHARDT and SCHRODER, 1983) and chemoembolization of hepatic tumors (AIGNER and GAILHOFER, 2005) and hence such arterial variations are very important and cannot be ignored.

\section{Case Report}

During dissection classes for medical undergraduates, we found variations in the branching pattern of celiac trunk in an adult male cadaver aged approximately 60 years. The celiac trunk divided into two branches; left gastric artery and hepato-splenic trunk. The hepato-splenic trunk was $2 \mathrm{~cm}$ long and it divided into splenic and common hepatic arteries. Splenic artery had a normal course and distribution. The common hepatic artery trifurcated into proper hepatic, gastroduodenal and accessory hepatic arteries. Hepatic artery proper was $1 \mathrm{~cm}$ long and divided into right and left hepatic arteries. The right and left hepatic arteries entered the right and left lobes of the liver through the porta hepatis. Gastroduodenal artery had a normal course, branching pattern and distribution. The accessory hepatic artery was tortuous and was as large as the left hepatic artery. It gave origin to the right gastric artery and entered the liver through left end of porta hepatis (Figure 1).

\section{Discussion}

Knowledge of anatomical variations in the branching pattern of the celiac trunk is important to surgeons during liver transplantation, laparoscopic surgery, radiological abdominal interventions and penetrating injuries to the abdomen. Since many of such vascular anomalies are asymptomatic, it should be kept in mind while handling patients who are undergoing diagnostic angiography for gastrointestinal bleeding, coeliac axis compression syndrome; prior to an operative procedure or transcatheter therapy (PIANO, OHTSUKA and MURAKAMI, 1988). 


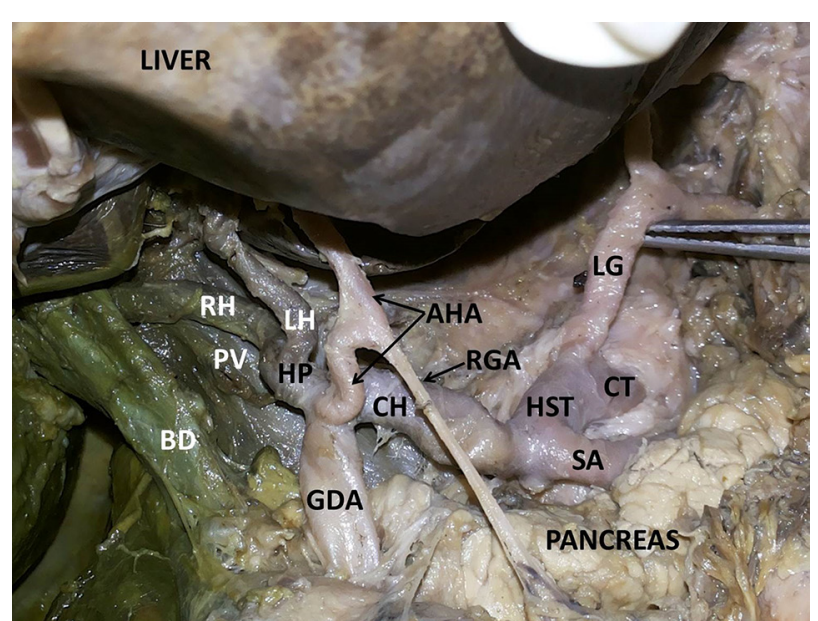

Figure 1. Showing the dissection of celiac trunk and its branches. CT - celiac trunk; HST - hepatosplenic trunk; SA - splenic artery; $\mathrm{CH}$ - common hepatic artery; AHA - accessory hepatic artery; $\mathrm{HP}$ - hepatic artery proper; RGA - right gastric artery; LG - left gastric artery; GDA - gastroduodenal artery; LH - left hepatic artery; RH - right hepatic artery; PV - portal vein; BD - bile duct.

Each dorsal aorta gives ventral splanchnic arteries which supply the gut and its derivatives. Initially, these ventral branches are paired but with the fusion of the dorsal aorta, they also fuse to form a series of unpaired segmental vessels which run in the dorsal mesentery of gut. They gradually fuse to form the arteries of foregut, midgut and hindgut (MOORE and PERSAUD, 2003). The persistence or unusual development of ventral splanchnic arteries may result in variations of celiac trunk and this may be the embryological basis of such type of variations. In 1953, Michels has classified the variations of celiac trunk into six different types: type 1- normal branching; type 2- hepato-splenic trunk and left gastric artery from aorta; type 3 - hepato-spleno-mesenteric trunk and left gastric artery from aorta; type 4- hepatogastric trunk and splenic artery from superior mesenteric artery; type 5- splenogastric type (splenic and left gastric from the celiac trunk and common hepatic artery from superior mesenteric artery) and type 6-celiacomesenteric trunk (splenic, left gastric, common hepatic and superior mesenteric arteries arise from a common trunk) (GIELECKI, ZURADA, SONPAL et al., 2005). However, he has not reported about the case of the bifurcation of celiac trunk into hepato- splenic trunk and left gastric artery as we have observed in our present case. A case slightly similar to our case has been reported by Chitra (2010) who had studied variations of the celiac trunk in fifty Indian cadavers and has found bifurcation in 3 cases. She has reported the presence of hepato-splenic trunk from celiac trunk and left gastric artery from aorta, but in our case left gastric artery arose from the celiac trunk. We also observed an unusual rare variation wherein the right gastric artery took its origin from the accessory hepatic artery. Nayak et al. (2012) have reported a case where the right gastric artery arose from left hepatic artery. Laparoscopic-assisted distal gastrectomy and open total or subtotal gastectomy involves the ligation and division of the gastric vessels. In laparoscopic surgery, since the operative field is relatively limited, there is every chance of ligation or division of the wrong vessel due to a lack of awareness of the anatomical variations involving the gastric vessels, which may lead to bleeding and ischemia or necrosis of the organ being operated upon (PRAKASH, RAJINI, MOKHASI et al., 2012).

In the present case we also observed an interesting variation of trifurcation of the common hepatic artery. The common hepatic artery trifurcated to give origin to proper hepatic artery, gastroduodenal and accessory hepatic artery. Hepatic artery proper divided into right and left hepatic arteries while the accessory hepatic artery was tortuous and was as large as the left hepatic artery. It entered the liver through left end of porta hepatis after giving out the right gastric artery. Chiang, Chang, Lee et al. (2005) have studied 405 patients angiographically for the evaluation of hepatic artery variations. They have reported the presence of a single accessory hepatic artery in $28.1 \%$ of cases, more than two hepatic arteries were found in $2.0 \%$ cases and seventeen patterns were identified; important ones being the origin of accessory hepatic artery from celiac trunk, as a branch from common hepatic, left gastric etc.

The anatomical variations of the hepatic artery are of great importance in general and hepatic surgery, especially in liver transplantation and vascular radiology. Recently, the arterial vascular anatomy of the liver has played a significant clinical role following the considerable development of hepato-pancreatobiliary surgery, the introduction of laparoscopic surgery, and the constant development of liver transplantation procedures. Knowledge of variations of hepatic artery is essential for a transplant surgeon in order to prevent vascular damage, and also in many radiological procedures such as transarterial chemo-embolization for hepatic tumors (XU and ZHENG, 2006). Thus surgeons and clinicians must be aware of such variations.

\section{Conclusion}

Even though many variations of celiac trunk have been reported in the past, bifurcation of celiac trunk and trifurcation of the common hepatic artery is a very rare variation. Presence of arterial variations may result in misinterpretation of angiograms. Thus, knowledge of such variations is important for proper pre-operative diagnosis and planning of surgical and radiological procedures and for interventional radiologists performing arteriography.

\section{References}

AIGNER, KR. and GAILHOFER, S. Celiac axis infusion and microembolization for advanced stage III/IV pancreatic cancer-a phase II study on 265 cases. Anticancer Research, 2005, vol. 25, n. 6C, p. 4407-4412. PMid:16334117.

BERGMAN, RA., AFIFI, AK. and MIYAUCHI, R. Anterior inferior cerebellar and posterior inferior cerebellar arteries. In: Illustrated encyclopedia of human anatomic variation: Opus II: cardiovascular system: arteries: head, neck, and thorax. Anatomy Atlases, 2011. Available from: <http://www.anatomyatlases.org/ AnatomicVariants/ Cardiovascular/Text/Arteries/CerebellarAntPostInferior.html>. Access in: 06 June 2014.

CHIANG, K., CHANG, P., LEE, P., LING, C., LEE, W., LEE, C. and $\mathrm{CHOU}, \mathrm{S}$. Angiographic evaluation of hepatic artery variations in 405 cases. Chinese Journal of Radiology, 2005, vol. 30, p. 75-81.

CHITRA, R. Clinically relevant variations of the coeliac trunk. Singapore Medical Journal, 2010, vol. 51, n. 3, p. 216-219. PMid:20428743. 
GIELECKI, J., ZURADA, A., SONPAL, N. and JABEOŃSKA, B. The clinical relevance of coeliac trunk variations. Folia Morphologica, 2005, vol. 64, n. 3, p. 123-129. PMid:16228946.

GLUCK, E., GERHARDT, P. and SCHRODER, J. Value of vascular morphology for the selection of catheters in selective celiacography and mesentericography. Rofo, 1983, vol. 138, n. 6, p. 664-669. PMid:6407931.

HEMANTH, K., GARG, S., YADAV, TD., SAHNI, D. and SINGH, $\mathrm{R}$. The hepatogastro-phrenic trunk and the hepato-spleno-mesentric trunk: a rare anatomic variation. Tropical Gastroenterology, 2011, vol. 32, n. 1, p. 56-59. PMid:21922858.

LIN, J. Celiomesenteric trunk demonstrated by 3 -dimensional contrast-enhanced magnetic resonance angiography. Hepatobiliary \& Pancreatic Diseases International, 2005, vol. 4, n. 3, p. 472-474. PMid:16109540.

MOORE, KL. and PERSAUD, TVN. The developing human (clinically oriented embryology). 7th ed. Philadelphia: Saunder, 2003. 335 p.

NAYAK, BS., SUDARSHAN, S., MADHAV, NV. and SRINIVASA RAO. Unusual branching pattern of common hepatic artery: a case report. International Journal of Anatomical Variations, 2012, vol. 5, p. 126-127.
PIANO, DX., OHTSUKA, A. and MURAKAMI, T. Typology of abdominal arteries, with special references to inferior phrenic arteries and their esophageal branches. Acta Medica Okayama, 1988, vol. 52, n. 4, p. 189-196.

PRAKASH, RAJINI, T., MOKHASI, V., GEETHANJALI, BS., SIVACHARAN, PV. and SHASHIREKHA, M. Coeliac trunk and its branches: anatomical variations and clinical implications. Singapore Medical Journal, 2012, vol. 53, n. 5, p. 329-331. PMid:22584973.

STANDRING, S. Gray's Anatomy: anatomical basis of clinical practice. 40th ed. New York: Elsevier Churchill Livingstone, 2008. 1073 p.

UCERLER, H. and IKIZ, ZAA. Multiplicity of the variations in the ventral branches of abdominal aorta. Italian Journal of Anatomy and Embryology, 2006, vol. 111, n. 1, p. 15-22. PMid:16736714.

$\mathrm{XU}, \mathrm{X}$. and ZHENG, SS. Variations and reconstruction of the hepatic artery in liver transplantation. Hepatobiliary \& Pancreatic Diseases International, 2006, vol. 5, n. 2, p. 170-172. PMid:16698569.

Received June 6, 2014 Accepted November 17, 2015 